\title{
NATUREZA, SOCIEDADE E CULTURA: A AMAZÔNIA (RE) INVENTADA A PARTIR DE SEUS TOPÔNIMOS
}

\section{Nature, society and culture: the Amazon reinvented from its toponyms}

\author{
Juliana Araújo ALVES ${ }^{1}$ \\ Susane Patrícia Melo de LIMA² \\ Waldemir Rodrigues COSTA JÚNIOR ${ }^{3}$ \\ Rogério Ribeiro MARINHO${ }^{4}$
}

\section{RESUMO}

Esta abordagem pauta-se na análise das toponímias, decifrando o seu papel no processo de significação e percepção dos lugares. A forma como os indivíduos identificam-se e territorializam-se com os lugares na Amazônia resulta dos processos de (re)ocupação influenciados por sujeitos ou "coisas"; valores religiosos (como os lugares com nomes advindos da fé católica e evangélica com representação de feições geográficas ou episódios bíblicos); interesses políticos (lugares com nome alusivos às de cidades portuguesas); e toponímias advindas dos aspectos naturais e culturais. Para Magalhães, "cada nome é uma descrição do objeto que representa, porque cada silaba diz uma idéia" (1940 apud MELLO, 1967, p. 162). Logo, as toponímias amazônicas possuem uma pluralidade referente aos valores individuais.

Palavras-chave: Amazônia; Toponímia; Identidade; Lugar.

\begin{abstract}
This paper is a staff analysis of toponyms by decoding its role in the process of meaning and perception of places. The way people identify themselves and territorialize the seats in the Amazon is a consequence of the processes of reoccupation, influenced by people or "things", such as religious values (like places with names derived from the catholic and christian faith with the representation of geographical features or biblical episodes); political matters (places with names of Portuguese cities); and toponyms originated of natural and cultural aspects. According to Magalhães, "each name is a description of the object it represents, because each syllable says one idea" (1940 apud MELLO, 1967, p. 162). Therefore, the toponyms of the Amazon are related to individual values in several ways.
\end{abstract}

Keywords: Amazon; Toponyms; Identity; Place.

1 Mestranda em Geografia pela Universidade Federal do Amazonas (UFAM) e pesquisadora do Núcleo de Estudos e Pesquisas das Cidades na Amazônia Brasileira (NEPECAB). E-mail: jalves. geografia@gmail.com

2 Mestranda em Geografia pela Universidade Federal do Amazonas (UFAM) e pesquisadora do Núcleo de Estudos e Pesquisas das Cidades na Amazônia Brasileira (NEPECAB). E-mail: susipatricia@gmail.com

3 Mestrando em Geografia pela Universidade Federal do Amazonas (UFAM) e pesquisador do Núcleo de Estudos e Pesquisas das Cidades na Amazônia Brasileira (NEPECAB). E-mail: junior.wrc@gmail.com

4 Mestrando pelo Instituto Nacional de Pesquisas Espaciais (INPE) e pesquisador do Núcleo de Estudos e Pesquisas das Cidades na Amazônia Brasileira (NEPECAB). E-mail: rogeriorm22@gmail.com 


\section{INTRODUÇÃO: OS LUGARES PELOS NOMES E OS NOMES PELOS LUGARES}

\begin{abstract}
Embora não tivessem condições de deixar por escrito esses conhecimentos, podemos hoje reconstruir uma pequena parcela do mesmo, graças a uma leitura correta dos nomes por eles atribuídos aos principais acidentes geográficos!
\end{abstract}

Vitor Leonardi

No estudo da Geografia Cultural, a toponímia pode ser utilizada para a compreensão dos lugares como dimensões ontológicas, isto é, está associada ao estudo da origem dos nomes dos lugares considerando os aspectos da dominação territorial, bem como o surgimento das identidades e significações para dado lugar. Os lugares enquanto seres (HOLZER, 1998), na Amazônia, estão enraizados na própria história de cada indivíduo, de maneira singular, e do povo, numa perspectiva pluralista. As pessoas se sentem parte dos seus lugares, bem como estes ao serem evocados pelo próprio nome reforçam o seu elo com os sujeitos.

A forma como os indivíduos identificam-se e territorializam-se com os lugares na Amazônia resulta dos processos de ocupação/(re)ocupação influenciados por sujeitos ou "coisas" (SANTOS, 2004, p. 64) e por interesses ou valores religiosos, como no caso das cidades com nomes relacionados à fé católica (nomes de santos) ou evangélica (nomes de feições geográficas bíblicas ou representações de episódios bíblicos), interesses políticos, como aquelas com nomes relacionados às cidades portuguesas, ou até mesmo as cidades que puderam ter seus nomes associados à fauna ou flora local, assim como outros dos seus recursos naturais e atributos culturais.

As toponímias amazônicas e sua dimensão cultural possuem uma pluralidade com simbolismos e identidades responsáveis pelas expressões dos valores individuais dentro de cada época, onde cada lugar foi sendo nomeado e ao mesmo tempo proporcionou um sentimento de pertencimento e domínio territorial. De acordo com Tuan (1983, p. 151) "o espaço transforma-se em lugar à medida que adquire definição e significado", pelo que a nomeação dos lugares é capaz de proporcionar esta definição e significado.

Através do batismo dos nomes dos lugares, ou seja, dos topônimos, criaram-se identidades, pertencimentos e territorialidades, que aos poucos foram sendo aceitas pelas comunidades. Na região Amazônica os lu- gares receberam nomes que indicam práticas, costumes e valores que em sua maioria refletiram identidades já existentes, ou seja, identidades daqueles que iniciaram o processo de implantação das cidades, pois "todos os lugares habitados têm nomes. A toponímia é uma herança preciosa das culturas passadas" (GONÇALVES, 2007, p. 73).

Neste sentido, este trabalho tem por objetivo decifrar os significados e o papel da toponímia na transformação do espaço amazônico, bem como, entender que pelo nome dos lugares é possível perceber a relação simbólica que determinado lugar desenvolve ou desenvolveu em outras épocas, tendo em vista que "uma pessoa pode conhecer um lugar tanto de modo íntimo como conceitual" (TUAN, 1983, p. 7). E por esta perspectiva, o modo íntimo relaciona-se com os que vivem o lugar, e o conceitual, relacionado à percepção dos que chegam a este lugar.

As toponímias, dependendo do contexto em que o indivíduo se insere num tempo e espaço, levam os sujeitos a transcenderem a dimensão física dos lugares, de forma que nem o tempo cronológico e nem mesmo as fronteiras físicas que os limitam se tornam barreiras. Isto se remete à fluidez com que a percepção e a experiência levam os sujeitos a se relacionarem com os lugares tornando estáveis às sensações que a cada dia os sujeitos imprimem nas espacialidades.

\section{TOPONÍMIAS AMAZÔNICAS: O SIMBOLISMO DOS LUGARES}

Victor Leonardi sustenta que a toponímia dos lugares na Amazônia "[...] quase sempre possuem uma relação muito íntima com a fauna da área, ou com alguma característica da água (coloridade, porosidade da água) e do solo" (LEONARDI, 1999, p. 74). Para este autor, a toponímia apresenta-se como um importante indicador para a elaboração de mapa etno-ambiental das bacias hidrográficas da Amazônia, sendo dessa forma, importante relacionar o nome dos lugares com atributos locais.

O nome dos lugares quase sempre é atribuído a alguma característica física ou humana, relacionadas ao simbólico e ao lúdico da população desse lugar, enfim as peculiaridades destes lugares relacionam-se com questões étnicas, alegorizam, questões religiosas ou atributos físicos. Porém, Victor Leonardi salienta que "[...] os nomes - de igarapés, lagos e lugares - vêm do nheengatu" (LEONARDI, 1999, p. 73). Percebe- 
ALVES, J. A. et al. Natureza, sociedade e cultura: a Amazônia (re)inventada a partir...

se dessa maneira que o nome de alguns lugares são atributos indígenas derivados de troncos linguísticos, relacionados aos fatores geográficos que caracterizam um determinado lugar. Porém, cabe ressaltar, que não são só com os atributos indígeno-cultural-geográficos que estes nomes se identificam, mas também com as representatividades religiosas.

Como destaca Denis Cosgrove "O local é [...] altamente complexo, com múltiplos patamares de significados" (1989 apud CORRÊA; ROSENDAHL, 1998). Ele é antes de tudo fruto de particularidades, atributos únicos e inconfundíveis que permitem ao indivíduo reconhecê-lo em qualquer lugar, e quando estiver em outros lugares, percebê-lo de diferentes formas, transcendendo o lugar e envolvendo-se na topofilia de Yi- Fu Tuan (1983), na relação de pertencimento do indivíduo como e pelo lugar.

Denis Cosgrove adverte ainda que a Geografia deixa de atribuir à paisagem os fatores humanos reduzindo quase sempre o significado a "[...] uma impressão impessoal das forças demográficas e econômicas" (1989 apud CORRÊA; ROSENDAHL, 1998, p. 97). Para Kevin Lynch o nome e o significado dos lugares são "[...] importantes para a cristalização da identidade" e salienta que "reforçam fortemente as sugestões de identidade ou de estrutura que podem estar latentes na própria forma física" (LYNCH, 1997, p. 120).

Além do simbolismo, das características naturais e da relação de identidade que as toponímias possam evocar, cabe ressaltá-las sob uma visão política ou a partir da dominação que o Estado passa a desempenhar no território.

Para Corrêa (2008), no século XVIII, o governo do Grão-Pará ao instituir o Diretório dos Índios, resolve implementar uma série de topônimos portugueses, expressando a sua capacidade de introduzir no cotidiano de índios, negros, e portugueses, por exemplo, outras maneiras de fazê-los relacionarem-se com o ambiente, bem como de reorganizar cartograficamente o espaço. Neste sentido, as toponímias podem materializar no espaço o interesse de organismos, sejam eles estatais ou privados.

Sendo assim, para a compreensão das toponímias é fundamental que a olhemos a partir dos diferentes significados, já que, por se constituírem de maneira dinâmica, continuamente se (re)inventam no tempo e no espaço, sobrepondo-se valores socioeconômicos, políticos, religiosos e culturais. Trata-se de um misto de significados que, no âmbito do vivido, se readequam ou não às necessidades materiais do sujeito, que tem os nomes dos lugares como norteadores do ir e do vir. Com isso, "na cidade os lugares já estão institucionalizados, batizados para facilitar a orientação [...]" (GONÇALVES,
2007).

\section{A HERANÇA DOS VIAJANTES: A MANIFESTAÇÃO DE SUAS IDENTIDADES E SÍMBOLOS}

A Amazônia, como toda a América, foi explorada e desmistificada pelas grandes navegações do século $\mathrm{XV}$. A bordo dessas grandes navegações, os cronistas relatavam a colonização, a flora, a fauna e os lugares. Como destaca Werther Holzer "trata-se da descoberta de um Novo Mundo, intocado e desconhecido do europeu. Ele iria ser apropriado e assimilado (constituindo-se em paisagens), resultando na transmissão de experiências e na exigência de ações (que constituem os lugares)" (HOLZER, 2000, p. 112). Apesar dos relatos dos cronistas serem fontes eivadas de fantasias, como adverte Carlos Fausto (2000), eles refletem muitas das alusões externas destes para com os lugares da Amazônia.

Uma característica peculiar da Amazônia foi ter seus nomes atribuídos por viajantes colonizadores, inicialmente, em meados do século XVI. Quase sempre essa atribuição derivava dos atributos físicos e sociais do lugar de origem destes viajantes, por vezes transcendia para além do imaginário por meio de crenças, sendo estas as principais lendas e fantasias de outros lugares. O próprio nome "Amazônia" deriva desse aspecto, pois os colonizadores transportaram-na de uma lenda grega, atribuindo às índias guerreiras a denominação de amazona.

O simbolismo criado para a Amazônia, refletido na toponímia de seus lugares é muito mais considerado pela visão de uma alteridade, assim como, para Leandro Tocantins (1972), de que pela imagem de um rio cheio de mistérios, abrigo de criaturas monstruosas e imaginárias que transcendia o pensamento seiscentista. $\mathrm{Na}$ época, acreditava-se que o mundo era um tabuleiro e que ao fim do horizonte cair-se-ia no habitat destes seres fantamasgóricos.

De acordo com Mello (1967, p. 161) "quase todas as cidades do estado do Amazonas, tiveram, de início, uma denominação, que o civilizado julgou conveniente substituir, privando-lhes pelo menos, de possuírem um nome verdadeiramente original". Assim, percebese uma transposição das fantasias europeias para a Amazônia, que acarretaram na perda dos nomes de lugares anteriormente denominados pelos indígenas a fim de refletirem sua identidade e seus símbolos, ou seja, aquilo que lhes era uma particularidade. 
Segundo Octaviano Mello as toponímias amazônicas "[...] foram muito bem empregadas pelos nossos observadores e inteligentes ameríndios, não dispensaram um acidente da natureza, nem um acontecimento mesmo vulgar, [...] fixando-o ao local em que surgiu" (MELLO, 1967, p. 161). Nessa observação de Mello percebe-se a grande habilidade dos indígenas em relacionar o nome do lugar aos elementos naturais presentes no seu cotidiano.

\section{METODOLOGIA: NOS LIMIARES DA COMPREENSÃO E DA DISTRIBUIÇÃO DOS TOPÔNIMOS}

A área em estudo localiza-se na região norte do estado do Amazonas, no interflúvio dos rios Negro e Solimões (figura 1).

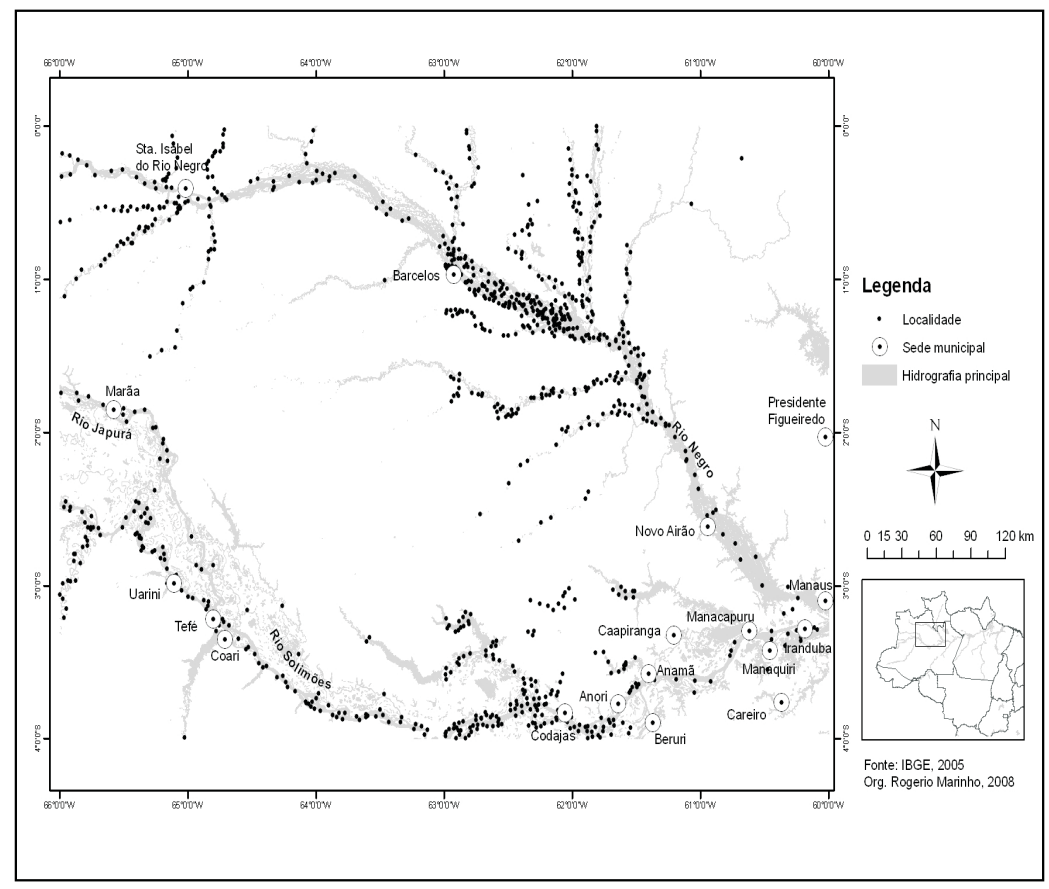

FIGURA 1 - MAPA DE LOCALIZAÇÃO DA ÁREA DE ESTUDO.

Org. MARINHO, Rogério. 2008.

Esta área foi selecionada por ser uma região de povoamento antigo. Foi utilizada a Carta Topográfica do IBGE (Instituto Brasileiro de Geografia e Estatística) SA20. Os dados foram reunidos em um Sistema de Informação Geográfica (SIG) extraindo toponímias das localidades e ilhas contidas na Carta Topográfica analisada.

Os Topônimos foram agrupados em nove categorias para que se pudesse inferir a análise espacial dos dados. As categorias foram: Fauna, Flora, Religião, Cultura Indígena, Personalidade Local e Aspectos Físicos da Região.

Para o processo de classificação e a espacialização da toponímia identificada foram utilizados os Dicionários Tupi-Português e O novo dicionário Aurélio da Língua Portuguesa (Versão 5.0. 3. ed.) a fim de associar os termos às respectivas categorias.

Contudo, através deste procedimento, não foi possível agrupar todos os nomes identificados, pois alguns lugares receberam denominações concernentes a sensações ou emoções da percepção humana, como "Felicidade" e "Esperança", logo, estes topônimos puderam estar no rol de lugares, que metodologicamente, denominou-se de "não agrupados".

Os topônimos evidenciados apresentam forte concentração ao longo das calhas dos rios Negro e Solimões, nos quais o processo de povoamento fora adentrando rios principais e seus respectivos afluentes. Estes mesmos rios foram, outrora, as principais rotas navegáveis pelos viajantes e naturalistas, que por sua vez perceberam uma diversidade de aspectos através dos quais novos topônimos surgiam. As características físicas dos dois rios são diferentes entre si, o que permite aferir que estes conjugam atributos diferenciados e esta diferença define também significados díspares. 
Mas não somente as características físicas dos rios são importantes para trazer a tona significados para os lugares, mas a própria geomorfologia destes pode acrescentar novos termos. Na Amazônia, a vastidão de atributos que a envolve, sejam feições ou processos (históricos, políticos ou sociais) deixam marcas no tempo e no espaço cristalizando a identidade dos lugares.

\section{PONDERAÇÕES ACERCA DOS LUGARES NA AMAZÔNIA}

Na região amazônica encontra-se mais de um terço das espécies de animais e plantas existentes no planeta. Além desta grande variedade no ecossistema, encontra-se uma grande diversidade cultural, sendo cerca de 180 povos indígenas, somente na Amazônia Brasileira, e uma vasta multiplicidade de povos com origem ou descendência europeia, afro-descendentes e oriundas de outras regiões do Brasil.
O universo da pesquisa correspondeu a 956 lugares e estes foram distribuídos conforme uma categoria de análise que evidenciou resultados de acordo com a tabela 01. Os nomes pelos quais os lugares são conhecidos manifestam aspectos da história, costumes, religião, fauna, flora e outros e com estes aspectos, seus habitantes se identificam representando, portanto, laços simbólicos.

TABELA 1 - CATEGORIAS E QUANTIDADE DOS LUGARES E SUAS TOPONÍMIAS

\begin{tabular}{|l|c|}
\hline \multicolumn{1}{|c|}{ Categoria } & No de lugares \\
\hline Fauna & 154 \\
\hline Flora & 125 \\
\hline Religião & 87 \\
\hline Cultura Indígena & 25 \\
\hline Personalidade Local & 75 \\
\hline Meio Físico (solo, hidrografia e geomorfologia) & 79 \\
\hline Não Agrupados & 411 \\
\hline Amostra Total & $\mathbf{9 5 6}$ \\
\hline
\end{tabular}

Org.: LIMA, ALVES, MARINHO, 2008.

Das toponímias que puderam ser categorizadas, prevaleceram os nomes com referência ao ecossistema amazônico, ou seja, toponímias derivadas de nomes de espécies animais e da vegetação, pelo que a figura 2 e 3 dá conta de espacializá-los conjugadas a alguns exemplos de topônimos identificados. 


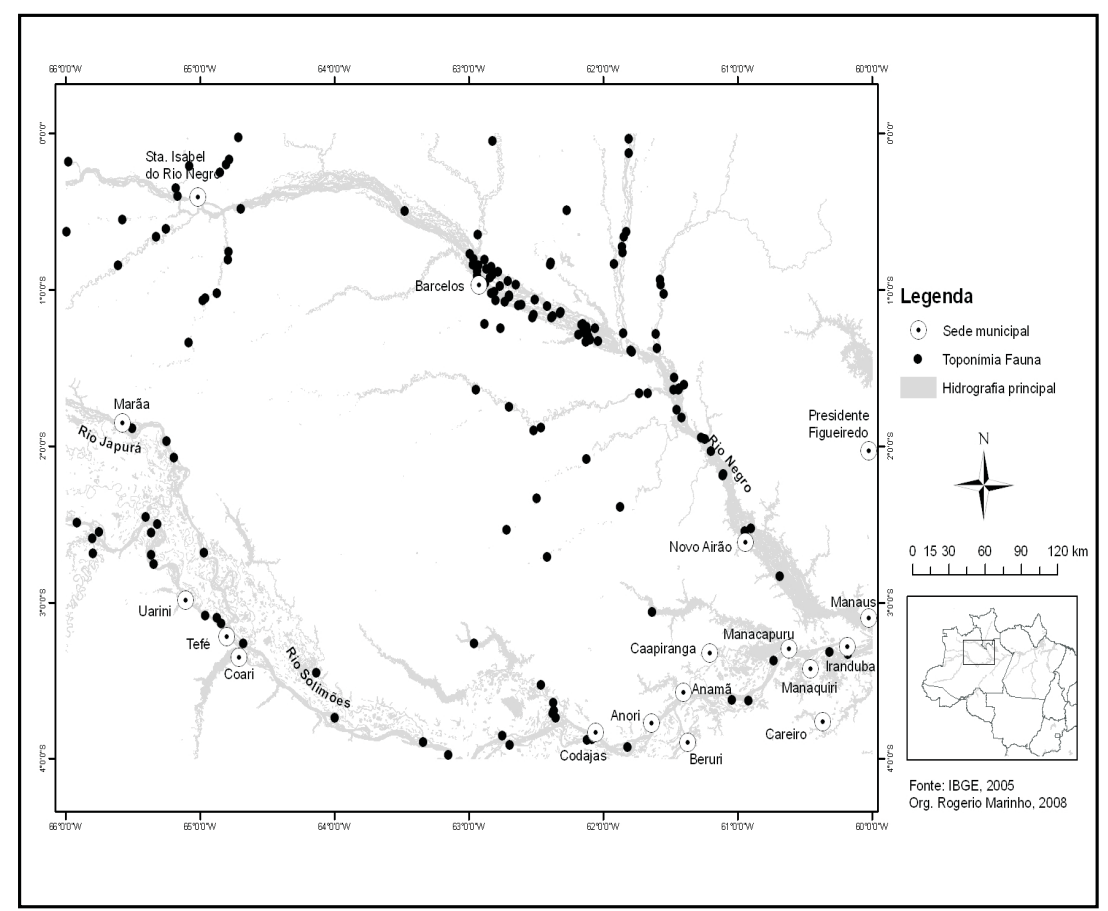

\begin{tabular}{|c|}
\hline Ilha Camaleão \\
\hline Ilha do Matrinxão \\
\hline Ilha das Onças \\
\hline Ilha Arraia \\
\hline Ilha do Inambu \\
\hline Ilha do Marrecão \\
\hline Arraiaquara \\
\hline Caititu \\
\hline Arraia \\
\hline Guajará \\
\hline Tucandira \\
\hline Caracoal \\
\hline Mucuí \\
\hline Cutia \\
\hline
\end{tabular}

FIGURA 2 - MAPA DE TOPONÍMIAS DE FAUNA E EXEMPLOS DE NOMES IDENTIFICADOS

Org. LIMA, ALVES, COSTA JR.,MARINHO, 2008.

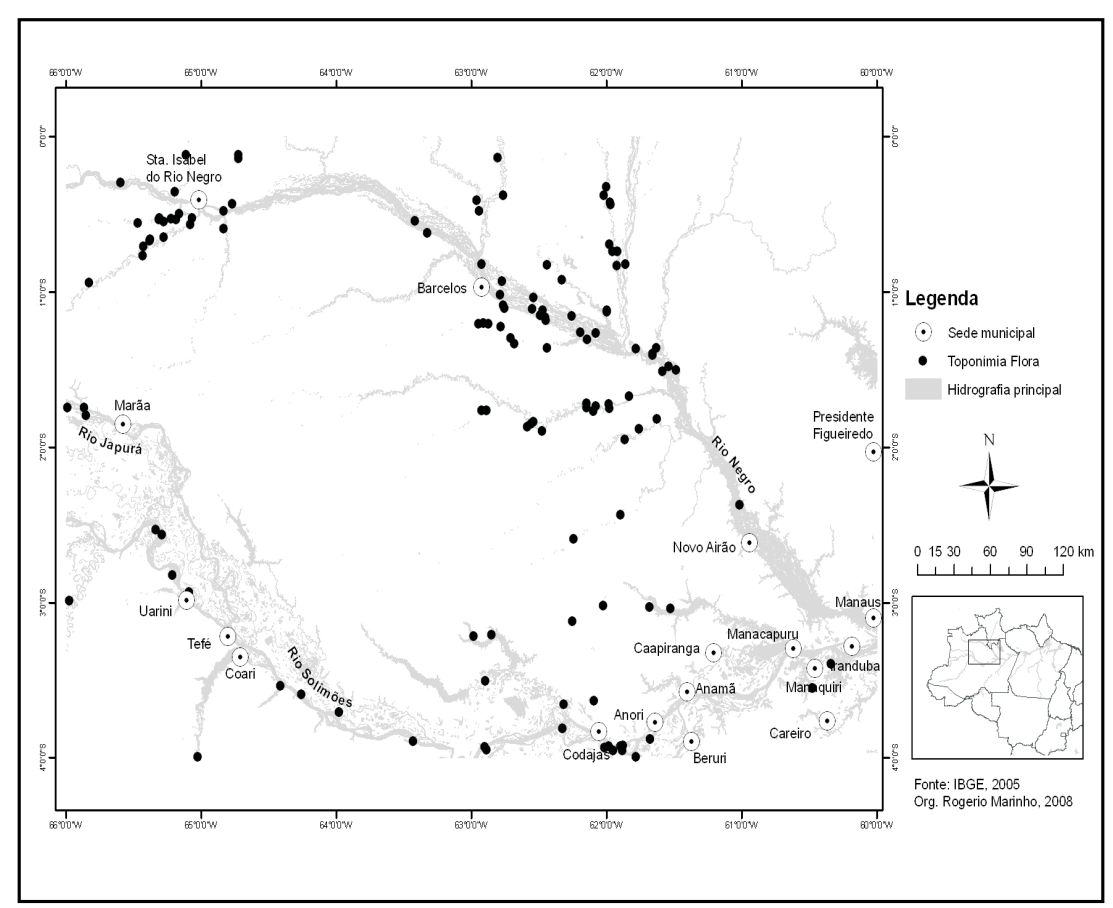

\begin{tabular}{|c|}
\hline Ilha Folharal \\
\hline Ilha Javaruna \\
\hline Ilha da Castanha \\
\hline Ilha da Maniva \\
\hline Ilha do Sapucaia \\
\hline Ilha do Castanho \\
\hline Ilha Bacabal \\
\hline Jutaí \\
\hline Andiroba \\
\hline Urucurizinho \\
\hline Taboca \\
\hline Caju \\
\hline Laranjal \\
\hline Caiambé \\
\hline Açaituba \\
\hline
\end{tabular}

FIGURA 3 - MAPA DE TOPONÍMIAS DE FLORA E EXEMPLOS DE TOPÔNIMOS IDENTIFICADOS.

Org. LIMA, ALVES, COSTA JR., MARINHO, 2008. 
A distribuição dos topônimos derivados da cultura indígena (figura 4) ficou espacializada de forma que evidenciou uma maior quantidade ao longo do Rio Negro e seus afluentes. Em relação à quantidade, apresentou-se incipiente quando comparados às demais categorias. Este fato está associado à chegada dos europeus na
Amazônia, pelo que deram nomes aos lugares sempre relacionando a seu mundo vivido, não levando em consideração os que já habitavam o lugar. Neste caso, podemos mencionar uma redenominação (CORRÊA, 2008 , p. 28) que identifica não apenas uma marca, mas um território imbuído da posse portuguesa.

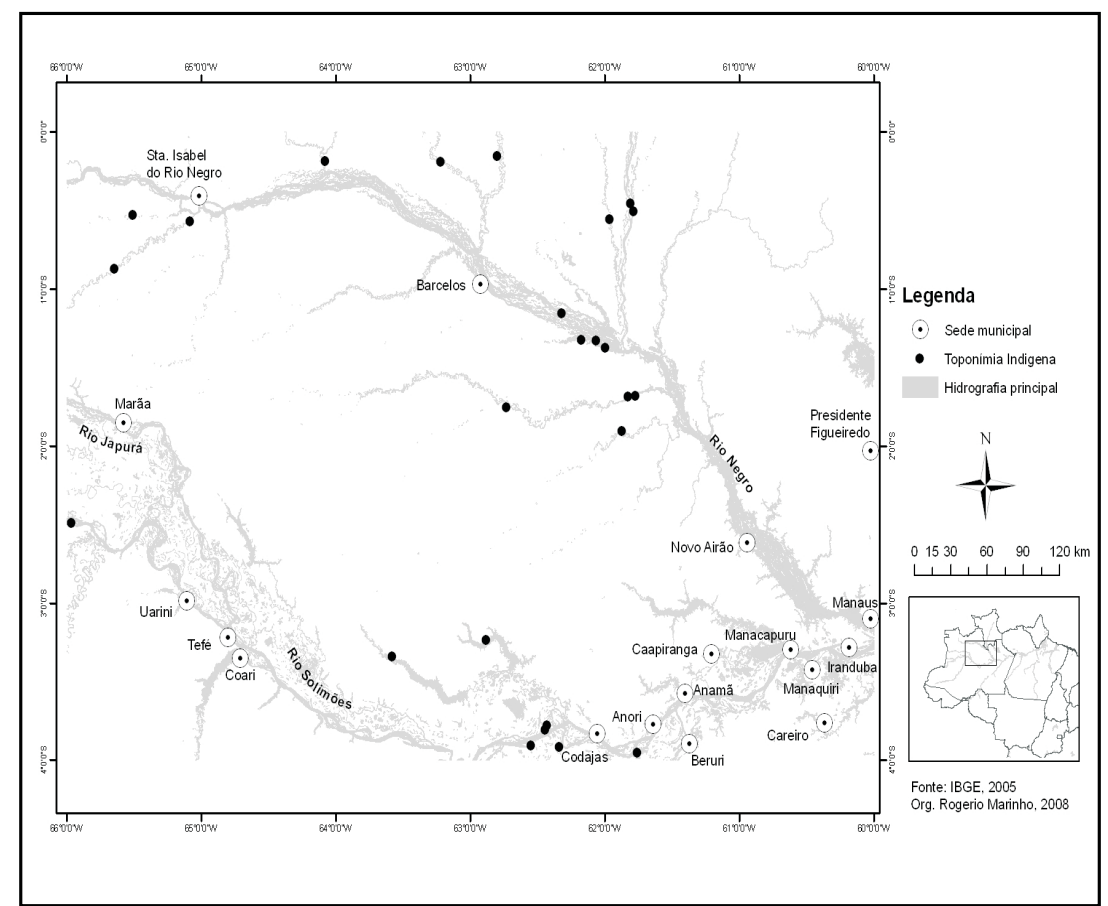

\begin{tabular}{|c|}
\hline Ilha do Balaio \\
\hline Ilha lara \\
\hline Ilha Jurupari \\
\hline Ilha Curupira \\
\hline Tapiira \\
\hline Curupita \\
\hline Tapera \\
\hline Curupira \\
\hline Buiuçu \\
\hline Jurupari \\
\hline Curupira \\
\hline Iça \\
\hline Boiaçu \\
\hline Jurupari \\
\hline Pajé \\
\hline Panema \\
\hline
\end{tabular}

FIGURA 4 - MAPA DE TOPONÍMIAS CULTURA INDÍGENA E EXEMPLOS DE TOPÔNIMOS IDENTIFICADOS

Org. LIMA, ALVES, COSTA JR.,MARINHO, 2008.

Os topônimos relacionados ao meio físico também possuíram certa recorrência, evidenciando o fato de que o Amazonas e na Amazônia como um todo, imperam feições geográficas bastante diversas e com expressividades que incidem na identificação percebida pelos que vivem o lugar. Aspectos relacionados ao solo, às características geomorfológicas, fazem parte da vivência e deixam marcas na memória, seria uma cristalização que permite com que alguém ao pensar em determinado lugar, associe este, a algo sobressalente no meio físico (figura 5). 
ALVES, J. A. et al. Natureza, sociedade e cultura: a Amazônia (re)inventada a partir...

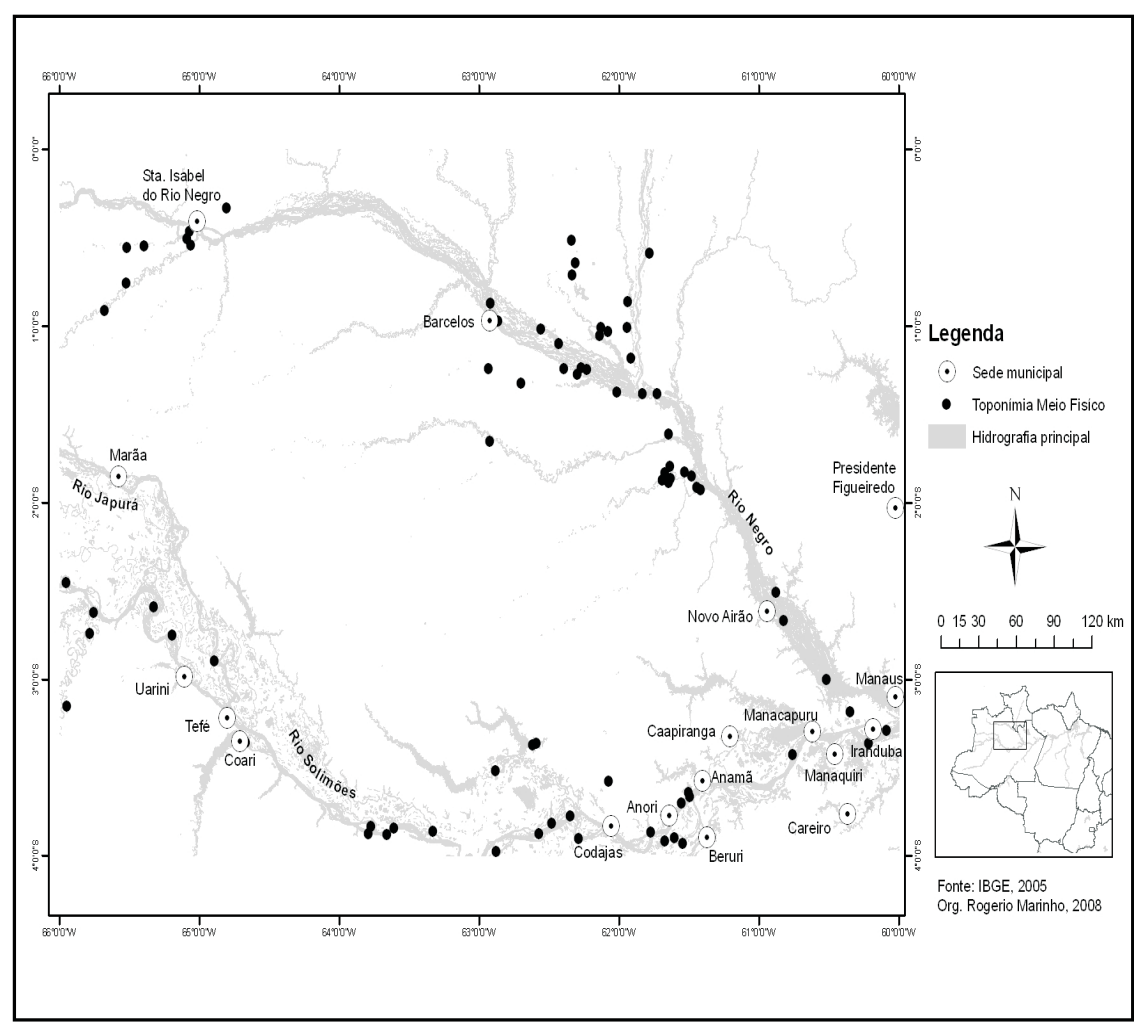

\begin{tabular}{|c|}
\hline Ilha do Purus \\
\hline Ilha do Baixio \\
\hline Ilha Sacada \\
\hline Ilha do Barro Alto \\
\hline Ilha Terra Preta \\
\hline Ilha Enseada \\
\hline Ilha do Depósito \\
\hline Ilha Japurá Grande \\
\hline Ilha da Praia Grande \\
\hline Ilha do Meio \\
\hline Costa do Gabriel \\
\hline Costa da Salvação \\
\hline Foz do Copeá \\
\hline Porto Quebra \\
\hline Barreiro \\
\hline Furo Curto \\
\hline Boca do Camarão \\
\hline Boca do Matrinxão \\
\hline Cachoeirinha \\
\hline Cachoeira do Jaú \\
\hline Solimõesinho \\
\hline
\end{tabular}

FIGURA 5 - TOPONÍMIAS MEIO FÍSICO E EXEMPLOS DE TOPÔNIMOS IDENTIFICADOS

Org. LIMA, ALVES, COSTA JR.,MARINHO, 2008.

Ao que se refere às toponímias categorizadas como personalidades locais e religião, estas se apresentam espacializadas conforme as figuras 6 e 7 . Nestas, estão imbricadas uma maior liberdade dos seus habitantes em relacionar os lugares a pessoas queridas ou a fé professada. Em geral, os nomes relacionados à religião carregam os simbolismos que determinam a forma como os indivíduos se identificam na dimensão religiosa e os valores que estes darão para seu domínio territorial.

As personalidades são escolhidas segundo seus feitos no lugar, a nomeação se dá em virtude do reconhecimento destes feitos e homenagem a tais personagens. A identidade que os indivíduos adquirem em relação ao lugar vincula-se às narrativas dos fatos que foram cristalizados na memória de seus habitantes.

Nem sempre os topônimos relacionados às personalidades são escolhidos pelos próprios habitantes, isso se dá também numa esfera política, quando autoridades locais impõem politicamente, nomes que por vezes não refletem nenhuma representatividade do lugar, e, portanto, deixam de estabelecer um elo de pertencimento não só com tal lugar, mas com os indivíduos deste lugar. Renomes por vezes surgem, mas os que vivem no lugar apresentam resistências e passam anos chamando por nomes anteriores que marcam suas próprias identidades. 


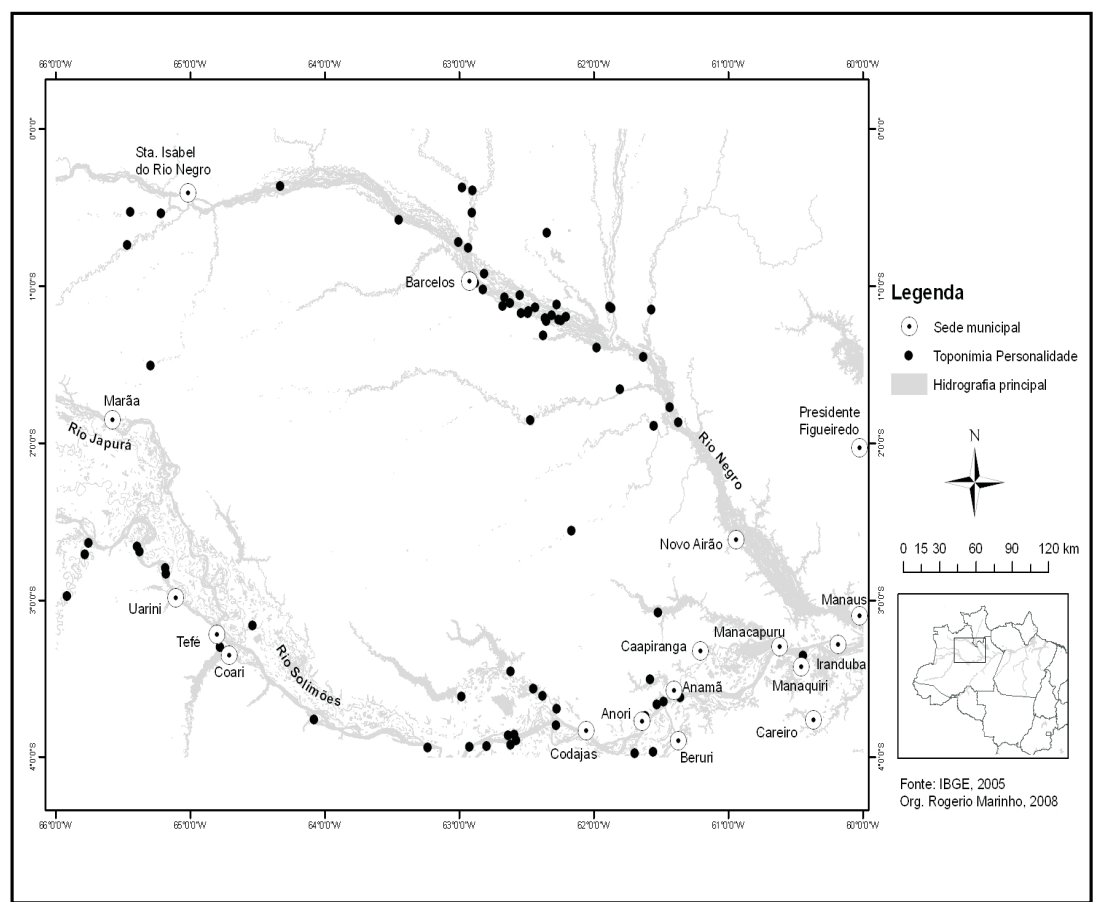

\begin{tabular}{|c|}
\hline Ilha Gabriel \\
\hline Ilha do Barroso \\
\hline Ilha Machado \\
\hline Ilha Juçara \\
\hline Ilha do Comandante \\
\hline Ilha do Fidélis \\
\hline Ilha do Abreu \\
\hline Ilha da Raimunda \\
\hline Ilha do Batista \\
\hline Ilha da Roberta \\
\hline Ilha do Cearense \\
\hline Alexandre \\
\hline Ernesto Guedes \\
\hline Porto Braga \\
\hline Moura \\
\hline Moreira \\
\hline Tiradentes \\
\hline
\end{tabular}

FIGURA 6 - MAPA DE TOPONÍMIAS PERSONALIDADE LOCAL E EXEMPLOS DE TOPÔNIMOS IDENTIFICADOS.

Org. LIMA, ALVES, COSTA JR., MARINHO, 2008.

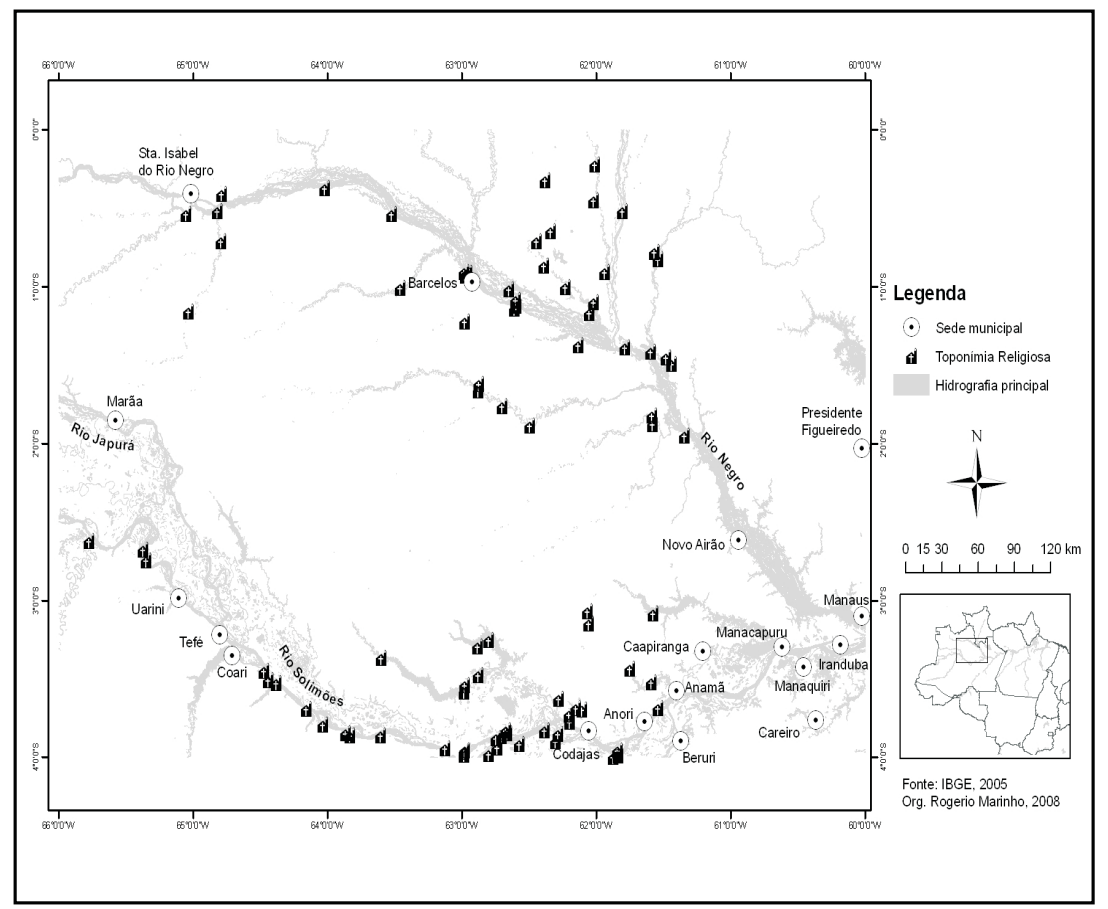

\begin{tabular}{|c|}
\hline Ilha Santa Marta \\
\hline Ilha Nova da Nazária \\
\hline Ilha São Domingos \\
\hline Ilha São Francisco \\
\hline Ilha Santo Antônio \\
\hline Ilha São José \\
\hline São José \\
\hline Santa Rosa \\
\hline São Francisco \\
\hline São Bento \\
\hline Santa Fé \\
\hline São Bento ou Esquecido \\
\hline Santa Maria \\
\hline São Domingos \\
\hline São Paulo \\
\hline São Francisco do Cas- \\
tanhal \\
\hline São João \\
\hline
\end{tabular}

FIGURA 7 - MAPA DE TOPONÍMIAS RELIGIÃO E EXEMPLOS DE TOPÔNIMOS IDENTIFICADOS.

Org. LIMA, ALVES, COSTA JR., MARINHO, 2008. 
ALVES, J. A. et al. Natureza, sociedade e cultura: a Amazônia (re)inventada a partir...

Observou-se uma maior concentração de lugares na calha do rio Negro, isto se deve a alta densidade de ilhas nesta região e ainda a presença do maior arquipélago do mundo, Anavilhanas, que compõe o Parque Nacional de Anavilhanas. Já na calha do rio Solimões, a maior concentração de lugares deu-se às proximidades da cidade de Codajás. Os nomes de lugares na Amazônia compõem um dinamismo que perpassam desde elementos naturais, culturais e políticos até os religiosos, evidenciando os inúmeros significados que a região possui e reafirmam no imaginário de quem vive e (re)cria a sua identidade com o lugar através de suas práticas vividas.

\section{CONSIDERAÇÕES FINAIS: DENOMINANDO OS LUGARES NA AMAZÔNIA}

O estudo sobre a espacialização de toponímias revelou que estas agregam os diferentes estágios do processo de povoamento ou ocupação da região amazônica. Imbricam-se com os processos espaciais e temporais. Por outro lado, representam uma justaposição de valores, significados, crenças, enfim, experiências de atores sociais que transpõem no espaço as suas visões de mundo.

Ressalta-se ainda que, embora tenham ocorrido imposições políticas alterando rapidamente os nomes de lugares na Amazônia, ou especificamente, no recorte deste trabalho, os topônimos continuaram - em

\section{REFERÊNCIAS}

CORREAA, Roberto Lobato. Região cultural: um tema fundamental. In: ROSENDAHL, Zeny. Espaço e cultura: pluralidade temática. Rio de Janeiro: EDUERJ, 2008. p. 11-43. (geografia cultural, v. 15).

CORRÊA, Roberto Lobato; ROSENDAHL, Zeny. Paisagem, tempo e cultura. Rio de Janeiro: EDUERJ, 1998.

COSGROVE, Denis. A Geografia está em toda parte: cultura e simbolismo nas paisagens humanas. In: CORREA, Roberto. L; ROSENDAHL, Zeny. Paisagem, tempo e cultura. Rio de Janeiro: EdUERJ, 1998. p. 92-122.

FAUSTO, Carlos. Os índios antes do Brasil. Rio de Janeiro: Jorge Zahar, 2000.

FERREIRA, Aurélio Buarque de Holanda. Novo Dicionário Aurélio da Língua Portuguesa. Versão 5.0. 3. ed. Curitiba: determinadas situações -, enraizados no cotidiano das pessoas. É como se para elas a troca do nome dos lugares as desorientassem no espaço e no tempo, pois as toponímias revelam a origem e a dinâmica dos lugares onde os indivíduos a cada dia apreendem conhecimentos do seu cotidiano, repassados de geração em geração. Incorporam-se novos topônimos, tornando rica a maneira pela qual as pessoas se utilizam da linguagem para imprimir no espaço uma variedade de significados.

As toponímias dizem respeito a heranças sócioculturais, revelando como as pessoas se relacionam com os seus lugares, pensam, vivem e experimentam o espaço em sua plenitude. Em outros termos, o espaço, ao ser alvo do processo de nominação, evidencia um conflito de interesses dos sujeitos que possuem diferentes papéis na sociedade.

A perspectiva metodológica desta pesquisa foi apenas uma dentre tantas outras possíveis para o estudo do processo de dinâmica territorial enfocando-se as toponímias de lugares. É possível articular uma série de conhecimentos numa perspectiva interdisciplinar para se compreender as toponímias como fenômeno de decifração da impressão das marcas do homem sobre a paisagem na Amazônia.

Esta porção norte do Brasil, o "Novo Mundo", de visões portentosas, a terra do "El Dourado", detentora dos "Anões do Purus" e tantas outras denominações as quais o outro utilizou para defini-la, será sempre o palco de (re)invenção com topônimos que irão impregnar em sua cultura e sociedade os significados de sua fauna, flora, religião, cultura indígena e, mais que isso, de seu povo.

Positivo, 2004

GONÇALVES, Teresinha Maria. Cidade e Poética: um estudo de psicologia ambiental sobre o ambiente urbano. ljuí: Ed. Unijuí, 2007, 208 p. (Educação em Ciência).

HOLZER, Werther. Memória de viajantes: paisagens e lugares de um novo mundo. Revista GEOgraphia, Ano II, n. 3, 2000.

. Um estudo fenomenológico da paisagem e do lugar: a crônica dos viajantes no brasil do século xvi. 257 f. Tese (Doutorado em Geografia) - Faculdade de Filosofia, Letras e Ciências Humanas, Universidade de São Paulo, São Paulo,1998.

LEONARDI, Victor. Os historiadores e os rios: natureza e ruína na Amazônia brasileira. Brasília: Paralelo 15, Editora Universidade de Brasília, 1999. 
LYNCH, Kevin. A imagem da cidade. São Paulo: Martins Fontes, 1997.

MELLO. Octaviano. Topônimos Amazonenses: nomes das cidades amazonenses, sua origem e significação. Série Torquato Tapajós. Manaus: Governo do Estado do Amazonas, 1967.

Dicionário Tupi-Português/Português-Tupi. 2. ed Manaus: Governo do Estado do Amazonas, Universidade Federal do Amazonas, 2003.
ROSENDAHL, Zeny; CORRÊA, Roberto Lobato. Espaço e Cultura: Pluralidade Temática. Rio de Janeiro: EDUERJ, 2008.

SANTOS, Milton. A natureza do espaço: técnica, tempo, razão e emoção. 4. ed. São Paulo: Edusp, 2004.

TOCANTINS, Leandro. O rio comanda a vida: uma interpretação da Amazônia, Rio de Janeiro: Companhia Americana, 1972.

TUAN, Yi-Fu. Espaço e Lugar: A perpectiva da experiência. São Paulo: Difel, 1983. 
